\title{
Comunicação
}

[Communication]

\section{Diagnóstico microbiológico e histopatológico de mortalidade em avestruzes (Struthio camelus)}

\author{
[Microbiological and histological diagnosis in mortality of ostrich (Struthio camelus)] \\ O. Vieira-da-Motta ${ }^{1}$, L.S. Silveira ${ }^{1}$, G.N. Teixeira ${ }^{1}$, C.B. Cardinot ${ }^{2}$, \\ L.S. Lemos ${ }^{1}$, R.S.T. Silva ${ }^{2}$, A.T. Branco ${ }^{2}$ \\ ${ }^{1}$ Centro de Ciências e Tecnologias Agropecuárias - UENF \\ Av. Alberto Lamego, 2000 \\ 28013-602 - Campos dos Goytacazes, RJ \\ ${ }^{2}$ Aluno de graduação - CCTA-UENF - Campos dos Goytacazes, RJ
}

\begin{abstract}
Avestruzes (Struthio camelus) podem ser acometidas por infecções bacterianas, principalmente na fase jovem, causando morte prematura de filhotes e prejuízos aos criadores (Carrer et al., 2004).
\end{abstract}

Pseudomonas aeruginosa figura entre os importantes patógenos em avicultura (Walker et al., 2002; Momotani et al., 1995), e Salmonella typhimurium, em avestruzes jovens na África do Sul (Verwoerd, 2000). A clostridiose também pode elevar a mortalidade de animais em cativeiro (Frazier et al., 1993; Lublin et al., 1993), e experimentos para fins profiláticos foram realizados em avestruzes, no Brasil (Schochen-Iturrino et al., 2001).

O óbito de 28 animais, no norte do estado do Rio de Janeiro, da eclosão até quatro meses de idade, sugere etiologia bacteriana, o que justifica o objetivo deste trabalho. Os casos compreenderam morte imediata à eclosão, letargia, inapetência e perda de peso progressiva após o nascimento.

Amostras de tecidos para microbiologia e histopatologia foram colhidas e semeadas imediatamente após a coleta e, para histologia, colhidas e fixadas em formol neutro tamponado a $10 \%$, processadas pela técnica de parafina e coradas pela hematoxilina e eosina. Com suabe, colheram-se conteúdo do saco vitelino e fezes do

Recebido em 18 de dezembro de 2007

Aceito em 14 de abril de 2008

E-mail: olney@uenf.br conteúdo intestinal, que foram cultivados em meios sólidos ${ }^{1}$. Após incubação $\left(37^{\circ} \mathrm{C} / 24 \mathrm{~h}\right)$, análise morfotintorial (Gram), teste IMViC e prova de oxidase ${ }^{2}$, as colônias foram identificadas em galerias (API 20 GN) e interpretadas em equipamento automatizado ${ }^{3}$.

As contaminações de ovos de avestruz são freqüentes e responsáveis pela diminuição da taxa de eclosão e do aumento da infertilidade e da infecção (Deeming, 1995; 1996). Quatro aves de ovos que não eclodiram apresentaram anasarca e distensão da região central da cavidade celomática, formando um saco com líquido sanguinolento junto à porção medial da parede da cavidade.

$P$. aeruginosa, E. coli (não hemolíticas e hemolíticas), Klebsiella pneumoniae, Serratia marcescens, Enterobacter aglomerans e Pseudomonas mendocina cresceram em ágar cetrimide, sangue e McConkey provenientes de fezes e de fragmentos de pulmões, fígado $\mathrm{e}$ mucosa intestinal e de conteúdo do saco vitelino. De uma ave de 14 dias com pleuropneumonia necrotizante e mineralização incipiente de padrão psamomatoso, isolou-se $P$. aeruginosa, sugerindo quadro de sepsis pelo agente. Amostras de 11 animais não apresentaram crescimento de microrganismos, e os resultados de conteúdo intestinal mostraram $E$. coli como o

\footnotetext{
${ }^{1}$ Acumedia, EUA.

${ }^{2}$ Difco, EUA.

${ }^{3}$ MiniApi, bioMérrieux, França.
} 
principal agente isolado. Sabe-se que E. coli pode causar mortalidade em criatório de avestruzes (Nardi et al., 2005), patos (Watts et al., 1993) e frangos (La Ragione e Woodward, 2002). Do único animal com isolamento de $K$. pneumoniae, pode-se inferir que o agente foi a causa mortis, tendo em vista o comprometimento de vários órgãos, com nódulos esbranquiçados nas vias aéreas, fígado e em todo o segmento intestinal. De acordo com Williams (1984) e Gross (1984), casos de bacteremia e óbito em aves resultam em perdas econômicas substanciais, pela alta mortalidade e condenação de carcaças na indústria avícola. Em marrecos brancos-de-pequim (Anas anas platyrhinchos), foram isolados microrganismos de aves que apresentaram bacteremia e saculite aérea, entre as quais bactérias Gram-negativo, classificadas pela metodologia utilizada nesta pesquisa (Watts et al., 1993). Pelo fato de $E$. coli ter sido a bactéria mais isolada $(11 / 19)$ no presente trabalho, e de acordo com o observado nas demais referências, sugere-se a maior participação desse microrganismo no óbito dos avestruzes, na região investigada.

Palavras-chave: avestruz, Struthio camelus, Enterobacteriacea, Pseudomonas spp.

\begin{abstract}
Several young ostrich, including nestlings, with lassitude and inappetence followed by death or victim of sudden death were immediately brought to diagnosis at an Animal Health Laboratory. At necropsy, animals presented hemorrhage and altered content of the vitelline sac, and necrotic foci in the small intestine; one animal showed necrotic pleuropneumonia with psammomatosus bodies in the lung parenchyma. The cultures from different samples revealed Escherichia coli, Pseudomonas aeruginosa, Klebsiella pneumoniae, Serratia marcescens, Enterobacter aglomerans, and Pseudomonas mendocina. It was suggested one case of septicemia in an animal with exclusive growth of $\mathrm{K}$. pneumoniae isolated from samples of small intestine, lung, and liver.
\end{abstract}

Keywords: ostrich, Struthio camelus, Enterobacteriacea, Pseudomonas spp.

\section{AGRADECIMENTOS}

À FAPERJ/CNPq, pelo apoio financeiro ao primeiro autor, processo FAPERJ E26/170.509/2004.

\section{REFERÊNCIAS BIBLIOGRÁFICAS}

CARRER, C.C.; ELMOR, R.A.; KORNFELD, M.E. et al. A criação de avestruz: guia completo de $A$ a $Z$. Pirassununga: Grupo Ostrich do Brasil, 2004. 256p.

DEEMING, D.C. Factors affecting hatchability during commercial incubation of ostrich (Struthio camelus) eggs. Br. Poult. Sci., v.36, p.51-65, 1995.

DEEMING, DC. Microbial spoilage of ostrich (Struthio camelus) eggs. Br. Poult. Sci., v.37, p.689-693, 1996.

FRAZIER, K.S.; HERRON, A.J.; HINES, M.E. et al. Diagnosis of enteritis and enterotoxemia due to Clostridium difficile in captive ostriches
(Struthio camelus). J. Vet. Diagn. Invest., v.5, p.623-625, 1993.

GROSS W.B. Miscellaneous bacterial disease. In: Diseases of poultry. HOFSTAD, M.S.; BARNES, H.J.; CALNEK, B.W. et al. (Eds). 8.ed. Ames, IA: Iowa State University, 1984. p.254-282.

LA RAGIONE, R.M.; WOODWARD, M.J. Virulence factors of Escherichia coli serotypes associated with avian colisepticaemia. Res. Vet. Sci., v.73, p.27-35, 2002.

LUBLIN, A.; MECHANI, S.; HOROWITZ, H. I. et al. A paralytic-like disease of the ostrich (Struthio camelus masaicus) associated with Clostridium chauvoei infection. Vet. Rec., v.132, p.273-275, 1993.

MOMOTANI, E.; KIRYU, M.; OHSHIRO, M. et al. Granulomatous lesions caused by Pseudomonas aeruginosa in the ostrich (Struthio camelus). J. Comp. Pathol., v.112, p.273-282, 1995.

NARDI, A.R.; SALVADORI, M.R.; COSWIG, L.T. et al. Type 2 heat-labile enterotoxin (LT-II)- 
producing Escherichia coli isolated from ostriches with diarrhea. Vet. Microbiol., v.105, p.245-249, 2005.

SCHOCKEN-ITURRINO, R. P.; URBANO, T.; TREMILIOSE NETO, G. et al. Bacterina experimental para clostridiose em avestruzes. In: REUNIÃO ANUAL DE ZOOTECNIA DA SOCIEDADE BRASILEIRA DE ZOOTECNIA, 38., 2001, Piracicaba. Anais... Piracicaba: SBZ, 2001. v.1, p.1513-1514.

VERWOERD, D.J. Ostrich diseases. Rev. Sci. Tech., v.19, p.638-661, 2000.

WALKER, S.E.; SANDER, J.E.; CLINE, J.L. et al. Characterization of Pseudomonas aeruginosa isolates associated with mortality in broiler chicks. Avian Dis., v.46, p.1045-1050, 2002.

WATTS, J.L.; SALMON, S.A.; YANCEY JR, R.J. et al. Minimum inhibitory concentrations of bacteria isolated from septicemia and airsacculitis in ducks. J. Vet. Diagn. Invest., v.5, p.625-628, 1993.

WILLIAMS J.E. Paratyphoid infections. In: HOFSTAD, M.S.; BARNES, H.J., CALNEK, B.W. et al. (Eds). Diseases of Poulty. 8.ed. Ames, IA: Iowa State University, 1984. p.91129. 